\title{
Examining Criteria for Adulthood Among Young People in Sabah (East Malaysia)
}

\author{
Walton Wider \\ INTI International University \\ Norazah Mohd Suki \\ Universiti Utara Malaysia \\ Melanie L. Lott \\ Brigham Young University - Provo \\ Larry J. Nelson \\ Brigham Young University - Provo, larry_nelson@byu.edu \\ Sew Kim Low \\ Universiti Utara Malaysia \\ Follow this and additional works at: https://scholarsarchive.byu.edu/facpub

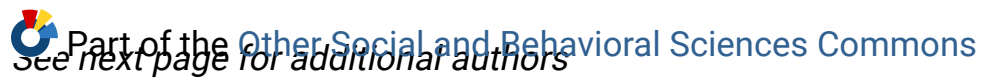

\section{Original Publication Citation}

Wider, W., Suki, N.M., Lott, M.L. et al. Examining Criteria for Adulthood Among Young People in Sabah (East Malaysia). J Adult Dev (2021). https://doi.org/10.1007/s10804-020-09367-9

\section{BYU ScholarsArchive Citation}

Wider, Walton; Suki, Norazah Mohd; Lott, Melanie L.; Nelson, Larry J.; Low, Sew Kim; and Cosmas, Gertrude, "Examining Criteria for Adulthood Among Young People in Sabah (East Malaysia)" (2021). Faculty Publications. 4714.

https://scholarsarchive.byu.edu/facpub/4714 accepted for inclusion in Faculty Publications by an authorized administrator of BYU ScholarsArchive. For more information, please contact ellen_amatangelo@byu.edu. 


\section{Authors}

Walton Wider, Norazah Mohd Suki, Melanie L. Lott, Larry J. Nelson, Sew Kim Low, and Gertrude Cosmas 


\title{
Examining Criteria for Adulthood Among Young People in Sabah (East Malaysia)
}

\author{
Walton Wider ${ }^{1}$ (D) Norazah Mohd Suki ${ }^{2}$ D $\cdot$ Melanie L. Lott ${ }^{3} \cdot$ Larry J. Nelson $^{3}$ (D) $\cdot$ Sew Kim Low $^{4}$ (D) $\cdot$ Getrude Cosmas $^{5}$
}

Accepted: 23 November 2020

(c) The Author(s), under exclusive licence to Springer Science+Business Media, LLC part of Springer Nature 2021

\begin{abstract}
This study aims to identify perceived adult status and to explore the criteria for adulthood of young people in Sabah (East Malaysia). The differences in such criteria based on gender and student status are also examined. Data collected from 208 respondents were analyzed via confirmatory factor analysis (CFA) and one-way analysis of variance (ANOVA). The empirical results of CFA revealed six criteria for adulthood: family capacities, norm compliance, interdependence, biological transitions, role transitions, and chronological transitions. However, the independence factor was discarded for further analysis because of having weak item loadings. In addition, the ANOVA test showed that women have higher interdependency and higher family capacities than men. Traditionally, women are more "other-oriented"-frequently thinking about the perspectives and needs of others - and are acknowledged as the main caregivers for children. Students are found to emphasize role transitions and biological transitions in determining their adulthood more than nonstudents. The present findings enable policymakers to obtain current emerging adults' views regarding the differences in criteria for adulthood based on gender and student status. Present findings permit a better understanding of the value of emerging adults' mental health as they encounter social, emotional, psychological, and physical challenges. This awareness would facilitate the provision of appropriate developmental programs for emerging adults to assist them in achieving adulthood. Directions for future research are also provided.
\end{abstract}

Keywords Emerging adulthood $\cdot$ Adult development $\cdot$ Culture $\cdot$ Gender $\cdot$ Structural equation modelling $\cdot$ Malaysia

Young people, or emerging adults, from various cultures sometimes consider themselves adolescents and sometimes as full adults. They often have a tendency to display risky behaviors, such as unprotected sex, substance abuse, binge drinking, and reckless driving (Arnett 2000; Dogan et al. 2015; Lowe et al. 2013; Petrogiannis 2011; Wider et al. 2015). Thus, exploring emerging adults' criteria for adulthood is necessary to enrich their attitudes, knowledge, and skills in facing competitive challenges. Most previous studies on emerging adulthood have focused on the situation

Walton Wider

walton.wider@newinti.edu.my

1 INTI International University, Nilai, Negeri Sembilan, Malaysia

2 Universiti Utara Malaysia, Sintok, Kedah, Malaysia

3 Brigham Young University, Provo, UT, USA

4 Universiti Tunku Abdul Rahman, Kampar, Perak, Malaysia

5 Universiti Malaysia Sabah, Kota Kinabalu, Sabah, Malaysia in Asian countries such as China (e.g., Nelson et al. 2012) and India (e.g., Seiter and Nelson 2011), and the issue has received minimal attention in the Malaysian setting. Nelson and Luster (2015) and Syed and Mitchell (2013) have stressed that further exploration of emerging adulthood based on racial and ethnic differences is warranted. In addition, Cheah et al. (2010) have asserted that gender socialization leads to gender differences in the criteria deemed necessary for adulthood.

In Malaysia, a developing nation, Act 668 of the 2019 amendment to the Youth Societies and Youth Development Act defines youth as those aged 30 years old or younger (Bernama 2019). Likewise, in youth societies, a change in the age of office bearers reduced the maximum age to 30 with the regulation that at the time of appointment, an individual must be below that age (Yunus and Landau 2019). In 2017, the average age of marriage in Malaysia was 29 years for men and 26 years for women (Department of Statistics Malaysia 2019). These figures are more or less similar to those in other countries, such as Poland with 29 years for 
men and 27 years for women (Liberska et al. 2018); Japan with 31 and 29 years (Ishida 2013); Austria with 32.4 and 30.0 years (Statistic Austria 2014); and China with 29 and 27 years (Xinhua 2018), respectively. These average ages of marriage suggest that the transition to emerging adulthood is prolonged in Malaysia. Opportunities for education may also contribute to variations in aspects of emerging adulthood (Seiter and Nelson 2011). Young people from rural areas in East Malaysia have little opportunity for higher education and are pushed into maturity at an earlier age (UNICEF Malaysia 2019). Cultural beliefs and values and the need to support their parents sometimes forces young people to engage in working life to be self-sufficient.

As the transition to adulthood in Malaysia deserves further empirical exploration, this study aims to identify perceived adult status, explore the criteria for adulthood of young people in Sabah (East Malaysia), and examine the differences in such criteria based on gender and student status. This study therefore produces significant findings from the East Malaysian (Sabah) perspective that advance the body of knowledge regarding perceived adult status and criteria for emerging adulthood, as well as differences based on gender and student status.

\section{Dimensions of Emerging Adulthood}

The theory of emerging adulthood by Arnett (2000) noted that for young people in many cultures, the years from 18 to the mid-to-late $20 \mathrm{~s}$ represent a distinct developmental stage marked by identity exploration, an in-between feeling, a focus on the self, and a sense of possibility for the future. Clearly, emerging adulthood is a time of instability since it often brings many changes in occupation, relationships, and living arrangements. Emerging adulthood is also characterized by a feeling of being in between adolescence and adulthood (Nelson 2009) when changes in young people's perceptions of adulthood occur. Arnett (2001) believed that this extended period of feeling in-between is brought about in cultures with certain demographic conditions, including widespread education and training beyond secondary school and the postponement of marriage and parenthood until the late $20 \mathrm{~s}$ or beyond. However, Arnett also underscored the significance of cultural factors in determining whether or not emerging adulthood exists in a particular culture and, if it does, how it is experienced by young people in the culture and what factors young people believe contribute toward becoming adults.

In the past, role transitions such as marriage, completing education, and parenting were used as clear markers of adulthood (Schlegel and Barry 1991), but young people no longer perceive role transitions as necessary criteria (Nelson et al. 2007). As many young people are experiencing this developmental stage, researchers are exploring emerging adults' perceptions of adulthood and the criteria they believe are necessary for adulthood (Nelson et al. 2007; Nelson and Luster 2015). Indeed, many researchers have found that emerging adults have internal criteria for adulthood, such as accepting responsibility for the consequences of one's actions, forming mature relationships, and complying with societal norms (Arnett 1997, 2003; Dogan et al. 2015; Facio and Micocci 2003; Nelson et al. 2004; Seiter and Nelson 2011). Additionally, a growing body of work suggests that culture plays a role in determining the criteria that young people accept as prerequisites for adulthood (Arnett 2001).

\section{Cultural Factors in the Transition of Adulthood}

Culture affects emerging adulthood (Arnett 2014), and in this connection, there is a wide disparity between individualistic and collectivistic cultures (Nelson and Luster 2015). Western cultures give considerable importance to an individual's capacity to achieve self-sufficiency, while Eastern cultures tend to prioritize family and community goals, needs, and views (Cheah and Nelson 2004; Nelson et al. 2004). Emerging adults in collectivistic countries such as China, India, Turkey, and Argentina tend to believe that norm compliance (e.g., avoiding drunk driving), interdependence (e.g., learning to control one's emotions), and family capacities (e.g., being capable of keeping family safe) are the important criteria for adulthood (Facio and Micocci 2003; Nelson et al. 2012; Seiter and Nelson 2011).

Research examining the role of culture in shaping views of adulthood criteria is now exploring Asian countries where, generally, collectivistic values are reflected. However, much variance also occurs in cultural beliefs, traditions, and behaviors, thereby presenting a need to examine more closely some of the Asian cultures that have received less attention in previous studies. Malaysia, in particular, has received relatively little attention from researchers interested in the features of emerging adulthood. Thus, it is important to explore both the demographic characteristics and belief systems of Malaysia in order to understand the criteria that young people consider prerequisites for adulthood.

\section{Emerging Adulthood and Transition to Adulthood in Sabah (East Malaysia)}

Malaysia comprises peninsular Malaysia and East Malaysia (Sabah and Sarawak), a geographical area that shares a multiethnic culture with values that deserve further empirical exploration (Barlocco 2008). Sabah (East Malaysia) comprises many indigenous groups of people, including 42 
ethnic groups and over 200 sub-ethnic groups (Chan 2015; Pue and Sulaiman, 2013). People from Sabah identify themselves as the Sabahan and their main ethnicity as KadazanDusun. The Sabahan embrace more than one religion among their family members (Golingai 2015) and value a spirit of mutual respect, harmony, goodwill, and tolerance, with strong interdependency, marital ties, familial relationships, and norm compliance (Sokial 2006).

The interdependency value can be seen in the concept of "hot" and "cold." An offence (e.g., beating another's child, adultery) is thought to bring "heat" (i.e., it is under some kind of curse) and can cause illness and disaster to society. Such offence requires a "cooling" down (i.e., warding off the bad luck) as an attempt to restore harmony in the society by paying a penalty in the form of sogit or babas (e.g., giving an animal to be slaughtered and eaten as a symbol of the end of hostility). These cultural values of harmony and responsibility to one another teach young people that becoming an adult includes acting to maintain harmony within relationships.

Next, the Kadazan-Dusun communities also highly regard marital ties and familial relationships, in which family roles remain steeped in the beliefs of Adat (customary law), namely affirmation toward patriarchy, men's control of women's sexuality, submission of a wife to her husband, and children's loyalty to parents (Hossain et al. 2007). On the other hand, female roles tend to center on maintaining the religious and domestic activities of the family (Gom et al. 2015; Regis et al. 1997). Women are more actively involved in the overall care, emotional regulation, and stimulation of children compared to fathers in the Kadazan-Dusun family (Hossain et al. 2007). These roles imply that family capacities (e.g., caring for children, running a household) are very important in defining adulthood among the Sabahans and that they place a strong emphasis on being prepared for family roles in women's transition to adulthood. However, research on gender influence in conceptualizing adulthood has been heavily based on Western samples (Norona et al. 2016) and minimally conducted in Asian settings, as stressed by preceding scholars (Wider et al. 2016, 2015; Zhong and Arnett 2014).

As for norm compliance, the production and drinking of alcohol has emerged as an aspect of identity of the KadazanDusun; they are characterized by their penchant for drinking alcoholic beverages, the unique drinks they produce, and drinking practices such as the habit of always accompanying pusas (certain types of food such as roasted pork) with alcohol (Barlocco 2008). However, while alcohol plays a large role in the Kadazan-Dusun community, its members simultaneously criticize its excesses; Kadazan-Dusun beliefs include living in moderation, working hard to reach success, and upholding one's duty toward the nation and God (Barlocco 2008). These values regarding alcohol use dictate the requirement for limits and boundaries. Because of the need to maintain harmony in the community and the approval of alcohol consumption, we can expect the endorsement of adulthood criteria that reflect compliance with societal norms (e.g., avoiding binge drinking, avoiding drunk driving).

In addition, the subjective experience of adulthood varies between young people who attend university and those who do not (Seiter and Nelson 2011). Specifically, nonstudents uphold higher levels of subjective adulthood than students because nonstudents emphasize traditional family roles and take greater responsibility for themselves and others (Luyckx et al. 2008). Nonstudents also mature earlier than their student peers, learn to be self-sufficient in primary and secondary school, and take care of themselves without supervision from parents. According to Jeffery et al. (1992), rural situations present unique challenges to young people concerning the processes of making career decisions. When emerging adults stay with their families, parents often appoint their oldest child to take care of the siblings and do the household tasks while parents are away for work. Such responsibilities given by parents might well contribute toward young people's conception of adulthood.

\section{Methods}

\section{Participants and Procedure}

This study was conducted on the North Borneo Island in Sabah (East Malaysia), the second largest state in Malaysia, and focuses on emerging adults between 18 to 29 years old (Arnett 2016). Using a nonprobability snowball sampling technique, the first participant fulfilling the inclusion criteria was selected to complete the self-report survey administered via the Internet (link: https://freeonlinesurveys.com/s/ roD176jF\#L) through social networking sites like Facebook. The respondent was then asked to recommend another suitable participant within the age range to answer the survey. Data collection was held over a two-week period in October 2019 during which 250 responses were gathered. Because of incomplete surveys, 42 responses were removed from the collection; the remaining 208 questionnaires were usable for further analysis, equating to an $83 \%$ response rate. This sample size was large enough to fulfill the general rule suggested by O'Rourke and Hatcher (2013), who noted that a subject-to-item ratio should be $5: 1$. The present research required a minimum sample size of 195 since this study measured 39 traits.

Of the 208 respondents, women outnumbered men (33:17), and all respondents were unmarried emerging adults between 18 and 29 years old $(M=23.38 ; \mathrm{SD}=2.65)$. In addition, more than half of the respondents were full-time 
students (68.3\%), with $2.4 \%$ in school part-time and $31.7 \%$ not in school. In terms of employment status, $64.7 \%$ of the participants were unemployed, $25.2 \%$ were employed fulltime, and $10.1 \%$ were employed part-time. A majority of participants (51.9\%) were indigenous people of Sabah. This sample size met the requirements suggested by Minority Rights Group International (2016), namely that since more than half the population of Sabah comprises indigenous people of Sabah, the study sample size should also include more than half indigenous people of Sabah. Furthermore, 18.8\% of the respondents were Malay, $14.9 \%$ were nonindigenous people of Sabah, and $11 \%$ were Chinese. A small portion of the participants $(2.4 \%)$ were other ethnicities, and $1 \%$ were Indian. With regard to living arrangements, $47.8 \%$ of the respondents reported living with their parents, $24.2 \%$ reported living in an apartment or dormitory, $23.7 \%$ reported living in a rented house, $2.9 \%$ reported living in their own house, and $1.4 \%$ reported living in other types of residence.

\section{Measurements Used}

A two-section questionnaire was designed in English. Section A consisted of 12 questions about sociodemographic profiles, such as gender, age, highest level of education completed, current educational status, ethnic group, marital status, employment status, and father's and mother's highest level of education completed. In addition, some questions pertained to current living arrangements and religious beliefs. The final question related to adulthood status. In this respect, respondents who answered "yes" were categorized as "self-perceived adult," and those who indicated "no" or "in some respect yes, in some respect no" were categorized as "emerging adult."

The subsequent section, Section B, encompassed 39 measurement items adopted from Arnett (2003) to represent the seven criteria for adulthood: family capacities, norm compliance, interdependence, biological transitions, role transitions, chronological transitions, and independence. To be precise, family capacities were measured with eight items; norm compliance, eight; interdependence, four; biological transitions, four; role transitions, six; chronological transitions, three; and independence, six. These items were measured on a 4-point Likert scale extending from 1 (not at all important) to 4 (very important).

\section{Statistical Analysis}

A confirmatory factor analysis (CFA) was computed with structural equation modelling (SEM), using AMOS Version 21 to confirm the measurement items of the seven criteria for adulthood. SEM was chosen because Harris and Goode (2004) indicated that "structural equation models overcome the limitations of bivariate analyses through the simultaneous analysis of all the complex relationships between the variables" (p. 147). After that, a one-way analysis of a variance (ANOVA) test in the Statistical Package for the Social Sciences (SPSS) Version 21 was performed to assess the differences in the criteria for adulthood based on gender and student status.

\section{Results}

\section{Identification of Perceived Adult Status}

The descriptive analysis of adulthood status details that $39.4 \%$ of respondents felt they had achieved adulthood, $3.8 \%$ thought they had not, and $56.7 \%$ answered "in some respect yes, in some respect no." Those who reported that they had not achieved adulthood were combined with those who reported "in some respect yes, in some respect no," and this group was classified as emerging adults. These results suggested that a majority $(60.6 \%)$ of participants considered themselves to be emerging adults (i.e., not yet having reached adulthood), while $39.4 \%$ classified themselves as adults.

\section{Assessment of Criteria for Adulthood}

Criteria for adulthood were assessed via CFA through several tests, following suggestions given by Hair et al. (2010). The tests include fit indices, item reliability, convergent validity, and discriminant validity. Table 1 details the results of the fit indices of which the goodness of fit index (GFI) of 0.952 and the adjusted goodness of fit index (AGFI) of 0.955 surpassed the recommended fit level of 0.900 . Likewise, the comparative fit index (CFI) of 0.946 also topped the threshold of 0.900. In a similar fashion, the incremental fit index (IFI) and the normed fit index (NFI) of 0.961 and 0.963 , respectively outdistanced inception value of 0.900 . These results adhered to the suggestions given by Browne and Cudeck (1993). Additionally, the root mean square of approximation (RMSEA) of 0.064 was below the limit of 0.08 (Browne and Cudeck 1993; Hu and Bentler 1999), indicating an adequate fit. Overall, the results of the aforementioned goodness-of-fit indices of the model were satisfactory to proceed for further tests.

Next, the internal consistency for each factor was evaluated via Cronbach's alpha and composite reliability. Hair et al. (2010) noted that acceptable reliability existed when Cronbach's alpha and composite reliability values exceeded 0.70. Table 2 depicts that results for both analyses have surpassed the minimum permitted limit, demonstrating satisfactory reliability for each factor item. Furthermore, convergent validity was assessed by inspecting whether (a) item loadings $>0.70$, (b) average 
Table 1 Goodness-of-fit indices for measurement and structural model

\begin{tabular}{lll}
\hline Fit indices & $\begin{array}{l}\text { Recommended level } \\
\text { of fit }\end{array}$ & Measurement model \\
\hline Absolute fit measures & & \\
Chi-square $\left(\chi^{2}\right)$ & & 547.656 \\
Degree of freedom (df) & $>0.90$ & 242 \\
Goodness of Fit Index (GFI) & $<0.08$ & 0.952 \\
Root mean square of approximation (RMSEA) & & 0.064 \\
Incremental fit measure & $>0.90$ & 0.946 \\
Comparative Fit Index (CFI) & $>0.90$ & 0.961 \\
Incremental Fit Index (IFI) & $>0.90$ & 0.963 \\
Normed Fit Index (NFI) & $>0.80$ & 0.955 \\
Adjusted Goodness of Fit Index (AGFI) & & \\
Parsimony Fit Measures & $>0.50$ & 0.771 \\
Parsimony Comparative Fit Index (PCFI) & $>0.50$ & 0.768 \\
Parsimony Normed Fit Index (PNFI) & & \\
\hline
\end{tabular}

\begin{tabular}{|c|c|c|c|c|c|}
\hline Constructs & Scale items & $\begin{array}{l}\text { Standardiz- } \\
\text { edloading }\end{array}$ & Cronbach's alpha & $\begin{array}{l}\text { Composite } \\
\text { reliability }\end{array}$ & $\begin{array}{l}\text { Average vari- } \\
\text { ance extracted }\end{array}$ \\
\hline \multirow[t]{5}{*}{ Family capacities } & Fac_1 & 0.751 & \multirow[t]{5}{*}{0.767} & \multirow[t]{5}{*}{0.879} & \multirow[t]{5}{*}{0.593} \\
\hline & Fac_5 & 0.885 & & & \\
\hline & Fac_6 & 0.710 & & & \\
\hline & Fac_7 & 0.753 & & & \\
\hline & Fac_8 & 0.739 & & & \\
\hline \multirow[t]{4}{*}{ Norm compliance } & Noc_1 & 0.756 & \multirow[t]{4}{*}{0.702} & \multirow[t]{4}{*}{0.839} & \multirow[t]{4}{*}{0.566} \\
\hline & Noc_2 & 0.741 & & & \\
\hline & Noc_7 & 0.728 & & & \\
\hline & Noc_8 & 0.784 & & & \\
\hline \multirow[t]{3}{*}{ Interdependence } & Int_2 & 0.823 & \multirow[t]{3}{*}{0.713} & \multirow[t]{3}{*}{0.863} & \multirow[t]{3}{*}{0.678} \\
\hline & Int_3 & 0.860 & & & \\
\hline & Int_4 & 0.786 & & & \\
\hline \multirow[t]{3}{*}{ Biological transitions } & Bit_1 & 0.709 & \multirow[t]{3}{*}{0.739} & \multirow[t]{3}{*}{0.813} & \multirow[t]{3}{*}{0.593} \\
\hline & Bit_2 & 0.815 & & & \\
\hline & Bit_3 & 0.782 & & & \\
\hline \multirow[t]{5}{*}{ Role transitions } & Rot_1 & 0.849 & \multirow[t]{5}{*}{0.727} & \multirow[t]{5}{*}{0.892} & \multirow[t]{5}{*}{0.625} \\
\hline & Rot_2 & 0.883 & & & \\
\hline & Rot_3 & 0.735 & & & \\
\hline & Rot_4 & 0.719 & & & \\
\hline & Rot_5 & 0.752 & & & \\
\hline \multirow{3}{*}{$\begin{array}{l}\text { Chronological } \\
\text { transitions }\end{array}$} & Cht_1 & 0.749 & \multirow[t]{3}{*}{0.781} & \multirow[t]{3}{*}{0.829} & \multirow[t]{3}{*}{0.618} \\
\hline & Cht_2 & 0.864 & & & \\
\hline & Cht_3 & 0.740 & & & \\
\hline
\end{tabular}

Table 2 Confirmatory factor analysis (CFA) of the criteria for adulthood variance extracted (AVE) $>0.50$, and (c) composite reliability (CR) $>0.70$, by means of the Hair et al. (2018) recommendations. Falk and Miller (1992) reported that each construct had an acceptable convergent validity when its item loading was greater than 0.50 . Table 2 details that after removal of a total of 16 weak loading items (i.e., 3 -item of family capacities, 4 -item of norm compliance, 1-item of interdependence, 1-item of biological transitions, 1-item of role transitions, and 6-item of independence), 23 remaining factor items that act in accordance with the established thresholds (item loadings $>0.70$ ) were retained for further analysis. Also, the AVE values were greater than 0.50 , and the CR values were more than 0.70 . All in all, the convergent validity was satisfactory. 
Subsequently, discriminant validity among the constructs was checked by comparing the results of the square roots of the AVE with the correlation coefficients between the constructs (Fornell and Larcker 1981). The former need to be higher than the latter for confirming discriminant validity. Table 3 shows that the square roots of the AVE (in the diagonal) were higher than the correlation coefficients among the constructs. In addition, a correlation matrix of all the items as presented in Table 4 were below 0.700 , showing that multicollinearity is not an issue. These readings indicate a tolerable discriminant validity of the measurements.

Based on the above results, the measures used in this research strongly confirm reliability and validity of the criteria for adulthood. As a result, they permit an execution of further analysis, such as the ANOVA test.

\section{Differences in Criteria for Adulthood Based on Gender and Student Status}

The differences in the criteria for adulthood based on gender and student status were tested through an ANOVA test. Table 5 shows that interdependence and family capacities were considered significantly differently as a function of gender. Specifically, women were more likely than men to report interdependence $[F(1,206)=4.03, p<0.05]$ and family capacities $[F(1,206)=6.90, p<0.01]$ as important criteria for adulthood. In terms of student status, students were more likely than nonstudents to report role transition $[F(1,206)=11.07, p<0.01]$ and biological transition $[F(1,206)=5.14, p<0.05]$ as important criteria for adulthood.

Subsequent to the above analysis, the means for all $23 \mathrm{cri}-$ teria for adulthood were computed. Table 6 details the means and subscales for all items and ranks each item, resulting in five items emerging as the most important. These items are as follows:

1. Learning to have good control over your emotions $(M=3.89 ; \mathrm{SD}=0.37)$
2. Avoiding drunk driving $(M=3.89 ; \mathrm{SD}=0.38)$

3. Avoiding illegal drugs $(M=3.85 ; \mathrm{SD}=0.54)$

4. Avoiding committing petty crimes such as vandalism and shoplifting $(M=3.79 ; \mathrm{SD}=0.50)$

5. If a woman, become capable of caring for children $(M=3.71 ; \mathrm{SD}=0.56)$

The following items were rated as least important:

1. Being married $(M=2.91 ; \mathrm{SD}=0.96)$

2. Have at least one child $(M=2.93 ; \mathrm{SD}=1.00)$

3. Grow to full height $(M=2.96 ; \mathrm{SD}=1.00)$

Additionally, three aggregated sub-scales were rated as most important, namely norm compliance $(M=3.76$; $\mathrm{SD}=0.40)$, interdependence $(M=3.65 ; \mathrm{SD}=0.39)$, and family capacities $(M=3.60 ; \mathrm{SD}=0.44)$.

\section{Discussion}

This study identified perceived adult status and explored the criteria for adulthood of young people in Sabah (East Malaysia). Additionally, it examined the differences in such criteria based on gender and student status. The subsequent subsections furnish discussion on perceived adult status, criteria for adulthood, and differences in such criteria based on gender and student status.

\section{Perceived Adult Status}

The descriptive analysis revealed that the majority of the respondents did not consider themselves to be adults. Sabahan emerging adults who experience a status in between "adolescent" and "adult" occupied that space by being asked to accept responsibilities in the community and by being the oldest child in the family. These responsibilities include taking care of siblings and mingling with community members
Table 3 Correlation between factors

\begin{tabular}{llllllll}
\hline Variables & & 1 & 2 & 3 & 4 & 5 & 6 \\
\hline$(1)$ & Family capacities & 0.770 & & & & & \\
$(2)$ & Norm compliance & 0.088 & 0.752 & & & & \\
$(3)$ & Interdependence & $0.279^{* *}$ & $0.150^{*}$ & 0.823 & & & \\
$(4)$ & Biological transitions & $0.324^{* *}$ & $0.193^{* *}$ & $0.263^{* *}$ & 0.770 & & \\
$(5)$ & Role transitions & $0.179^{* *}$ & $0.259^{* *}$ & $0.144^{*}$ & $0.572^{* *}$ & 0.791 & \\
$(6)$ & Chronological transitions & $0.164^{* *}$ & $0.127^{*}$ & $0.210^{* *}$ & $0.548^{* *}$ & $0.454^{* *}$ & 0.786 \\
Means & & 3.680 & 3.590 & 3.580 & 3.000 & 3.390 & 3.470 \\
Standard deviation & & 0.350 & 0.390 & 0.440 & 0.720 & 0.520 & 0.670 \\
\hline
\end{tabular}

**Correlation is significant at the 0.01 level (1-tailed)

*Correlation is significant at the 0.05 level (1-tailed) 


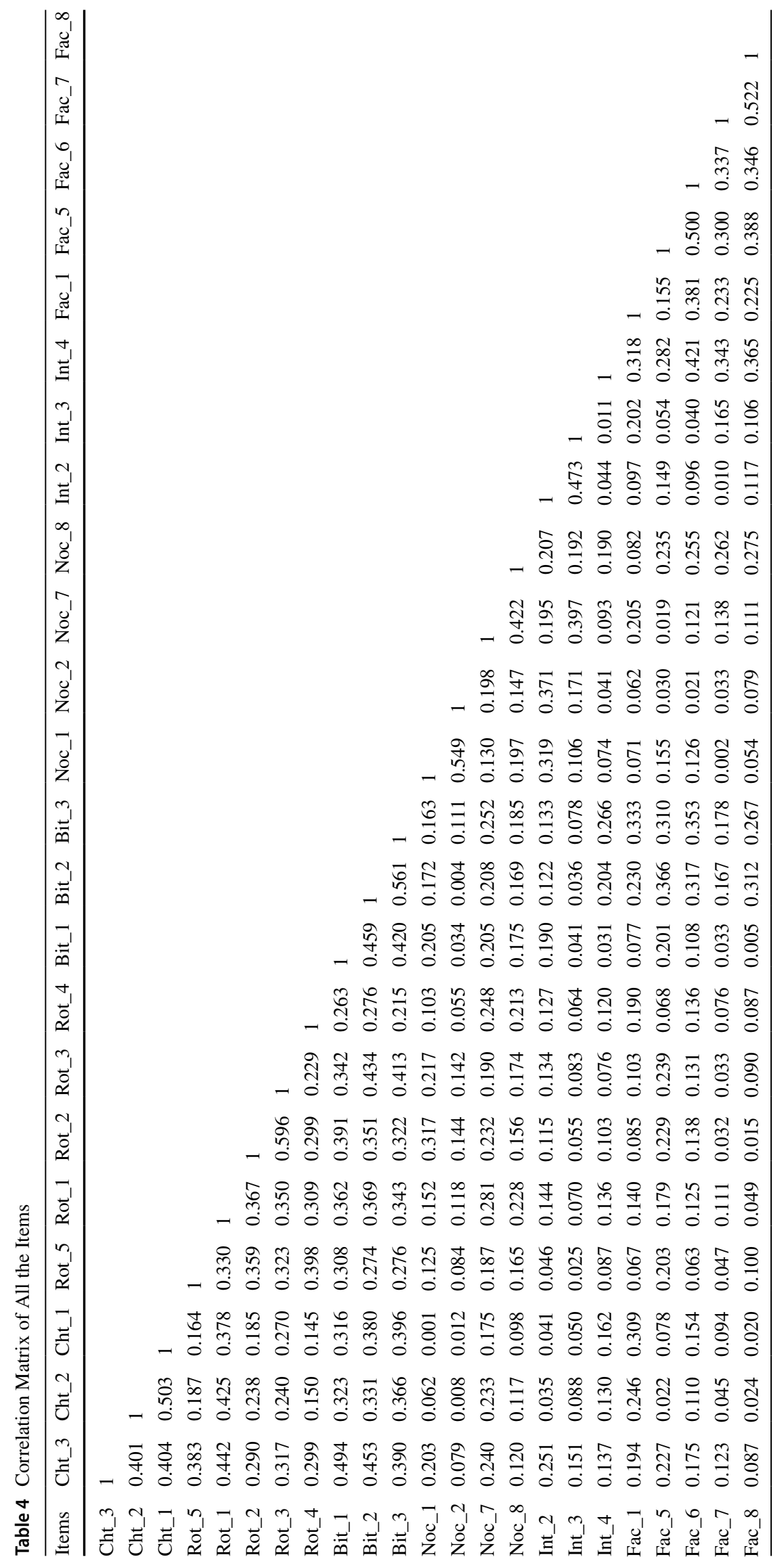


Table 5 Comparison of gender and student status in criteria for adulthood

Table 6 The importance of each criterion of adulthood

\begin{tabular}{|c|c|c|c|c|c|c|c|c|c|c|c|c|}
\hline \multirow[t]{3}{*}{ Dependent variable } & \multicolumn{6}{|c|}{ Gender } & \multicolumn{6}{|c|}{ Student status } \\
\hline & \multicolumn{2}{|c|}{ Male } & \multicolumn{2}{|c|}{ Female } & \multirow[t]{2}{*}{$\mathrm{F}$} & \multirow[t]{2}{*}{$\mathrm{df}$} & \multicolumn{2}{|c|}{ Student } & \multicolumn{2}{|c|}{$\begin{array}{l}\text { Nonstu- } \\
\text { dent }\end{array}$} & \multirow[t]{2}{*}{$F$} & \multirow[t]{2}{*}{$\mathrm{df}$} \\
\hline & $\mathrm{M}$ & SD & $\mathrm{M}$ & SD & & & $\mathrm{M}$ & SD & $\mathrm{M}$ & SD & & \\
\hline Interdependence & 3.64 & 0.39 & 3.65 & 0.40 & $4.03 *$ & 206 & 3.66 & 0.39 & 3.62 & 0.41 & 0.33 & 206 \\
\hline Role transitions & 3.34 & 0.54 & 3.35 & 0.58 & 0.65 & 206 & 3.43 & 0.52 & 3.18 & 0.62 & $11.07 * *$ & 206 \\
\hline Norm compliance & 3.71 & 0.40 & 3.79 & 0.39 & 0.82 & 206 & 3.77 & 0.40 & 3.75 & 0.39 & 0.15 & 206 \\
\hline Biological transitions & 3.16 & 0.81 & 3.26 & 0.75 & 1.18 & 206 & 3.08 & 3.31 & 3.03 & 0.70 & $5.14^{*}$ & 206 \\
\hline Chronological Transitions & 3.43 & 0.75 & 3.48 & 0.63 & 2.63 & 206 & 3.51 & 0.63 & 3.36 & 0.75 & 2.69 & 206 \\
\hline Family capacities & 3.52 & 0.50 & 3.63 & 0.41 & $6.90 * *$ & 206 & 3.62 & 0.45 & 3.54 & 0.43 & 0.08 & 206 \\
\hline
\end{tabular}

$* p<0.05 ; * * p<0.01$

\begin{tabular}{lll}
\hline Criteria & Mean & SD \\
\hline Family capacities & 3.60 & 0.44 \\
If a woman, become capable of supporting a family financially & 3.43 & 0.71 \\
If a woman, become capable of caring for children & 3.71 & 0.56 \\
If a man, become capable of caring for children & 3.69 & 0.55 \\
If a man, become capable of running a household & 3.57 & 0.65 \\
If a woman, become capable of running a household & 3.59 & 0.65 \\
Norm compliance & 3.76 & 0.40 \\
Avoid becoming drunk & 3.52 & 0.82 \\
Avoid illegal drugs & 3.85 & 0.54 \\
Avoid drunk driving & 3.89 & 0.38 \\
Avoid committing petty crimes such as vandalism and shoplifting & 3.79 & 0.50 \\
Interdependence & 3.65 & 0.39 \\
Make life-long commitments to others & 3.48 & 0.76 \\
Learn always to have good control over your emotions & 3.89 & 0.37 \\
Become less self-oriented, develop greater consideration for others & 3.59 & 0.61 \\
Biological transitions & 3.22 & 0.77 \\
Grow to full height & 2.96 & 1.00 \\
If a woman, become biologically capable of bearing children & 3.30 & 0.91 \\
If a man, become biologically capable of fathering children & 3.40 & 0.85 \\
Role transitions & 3.35 & 0.55 \\
Finish education & 3.70 & 0.65 \\
Have at least one child & 2.93 & 1.00 \\
Married & 2.91 & 0.96 \\
Settle into a long-term career & 3.63 & 0.60 \\
Purchase a house & 3.57 & 0.72 \\
Chronological transitions & 3.47 & 0.67 \\
Reached age 21 & 3.48 & 0.81 \\
Reached age 18 & 3.38 & 0.85 \\
Have obtained a driver's license & 3.54 & 0.75 \\
\hline
\end{tabular}

during activities such as Mitatabang (working together and helping each other, particularly during harvesting paddies, cleaning farms, or building houses). These individuals feel like adolescents when they are with their peer groups and engaging in sport and recreational activities without adult supervision. Previous studies have shown that peers often have considerable influence on young adult behavioral development (Hamzah et al. 2014). These discoveries concur with past studies from collectivist societies as found in countries such as China and India.

Nelson et al. (2004) found that $41 \%$ of Chinese university students did not consider themselves adults. A follow-up 
study by Nelson et al. (2012) reported that a higher percentage of Chinese university students did not consider themselves adults, while the study by Zhong and Arnett (2014) of migrant workers in China found that more than half (56\%) did not consider themselves adults. Meanwhile, the Seiter and Nelson (2011) study among Indian students and nonstudents reported that only $40 \%$ of the respondents did not consider themselves adults. Many have argued that emerging adulthood is mainly restricted to the middle-upper classes of Western, industrialized nations. Therefore, our findings commend Arnett's assertion in which there is a considerable variation worldwide of emerging adulthood experience in terms of demographic terms (Arnett 2011).

\section{Criteria for Adulthood}

The CFA derived six criteria for adulthood: family capacities, norm compliance, interdependence, biological transitions, role transitions, and chronological transitions. The independence factor from the original analysis was discarded for further analysis because of its weak item loadings. Of this, norm compliance, interdependence, and family capacities were ranked as the most important criteria for adulthood, respectively. To be exact, items such as "learn always to have good control over your emotions," "avoid drunk driving," "avoid illegal drugs," "avoid committing petty crimes such as vandalism and shoplifting," and "if a woman, become capable of caring for children" were ranked most important. This ranking illustrates that emerging adulthood exists for a segment of the population of Sabah, but a great difference exists within Sabah regarding how it is experienced. These results strengthen the works of Galambos and Martínez (2007), who assert that there is a lack of universal criteria for adulthood in Asia, especially in nonurban areas in developing countries. These criteria largely do not exist because of the age range and the differences among Asian countries regarding behaviors associated with adulthood (Nelson et al. 2004).

Descriptive analysis of the present study further revealed that "learning to control one's emotions" was ranked as the top criterion for adulthood among Sabahan young people. One possible explanation for this ranking is that these emerging adults view themselves as under their parents' control. Earlier studies have found that Asian parents demonstrate a more authoritarian parenting style (Pearson and Rao 2003) and that Asian adulthood tends to involve parental control in personal domains (Yau et al. 2009). Such control is perceived as an indicator of love and affection. Indeed, this control reflects the influence of Asian cultural values, which include the belief that positive emotion may be associated with interpersonal harmony (Deng et al. 2017). The goal to achieve and maintain interpersonal harmony demands the ability of Asian adults to regulate emotions (Fung and You
2011). Chinese adults who regulate their emotions have less negative emotional experiences (Deng et al. 2017).

Other findings similarly reflect that the role of culture includes both the broader collectivist values held in many Asian countries and more specific values and beliefs associated with Malaysian culture. For example, the importance that young people place on the criterion of family capacities for adulthood stands out as similar to that found in a study conducted among Indian emerging adults (Seiter and Nelson 2011). Specifically, the criterion "if a woman, become capable of caring for children" was rated highly in this study. As in India (Seiter and Nelson 2011), gender roles in Malaysia have typically outlined specific duties related to caregiving based on gender (Alavi 2012). Women are primarily responsible for taking care of the practical duties needed to run a household (e.g., washing clothes and preparing food), as well as giving emotional aid (e.g., talking about problems and giving advice). Men are primarily responsible for providing for the family through financial means (Eriksen and Gerstel 2002). Thus, the present results are in tandem with Sabahan culture, placing an emphasis on women being able to be good caretakers by providing care for children.

Finally, the cultural emphasis on mutual respect, harmony, and individual duty toward the nation and God appears to be reflected in the fact that young people rated norm compliance as the second most important criterion of adulthood. Specifically, three items ("avoid drunk driving," "avoid illegal drugs," and "avoid committing petty crimes such as vandalism and shoplifting") were highly rated. Taken together, these findings, along with an understanding of Sabahan culture, suggest that the transition to adulthood in Malaysia is a period of social responsibility and is not entirely self-focused (Katsiaficas et al. 2015). As in other Asian cultures, young people in Malaysia also emphasize collectivism and mark the importance of civic obligation in attaining adulthood (Wray-Lake and Syvertsen 2011).

Additionally, the study's participants ranked biological, role, and chronological transitions as the least important criteria for adulthood. During the twenty-first century, social and economic changes-such as compulsory education, establishing relationships, financial stability, and interdependence-may influence young people to reach adulthood later compared to previous generations where adulthood has been determined by chronological age. This finding is supported by previous studies, which claim that people place little importance on traditional role transitions to define adulthood (Brannen andd Nilsen 2002; Henig 2010; Jayson 2012). Furthermore, the complexity of modern society and young adult relationships cannot be explained solely by role, biological, and chronological transition in determining the markers of adulthood (Wyn and White 1997). Instead, transition to adulthood is seen as a multidimensional process in which young people may have different views and 
experiences (Westberg 2004). The role of culture may affect the individual's values, beliefs, and behavior, thus exerting an influence on young people's conception of adulthood. These findings are comparable with those of a study in Romania where college students emphasized the process of identity exploration rather than role transition in developing their feeling of being adults (Nelson 2009).

The growing importance of changes in the cultural, social, and economic environment may explain the low ranking of role, biological, and chronological transition as criteria of adulthood in this study. Individual maturity and taking responsibility for one's actions is the most common definition of adulthood (Arnett 1997). Previous studies have concluded that role transitions are reversible and insecure by nature (Wallace and Kovatcheva 1998; Wyn and White 1997). Additionally, marriage and childbearing have rarely been endorsed as role transitions (Arnett 1998; Nelson et al. 2007). The present study's findings coincide with those obtained by Weier and Lee (2015), whose findings demonstrated that personal maturity and environmental development determined adulthood.

\section{Differences in the Criteria for Adulthood Based on Gender and Student Status}

The ANOVA results reported differences in the criteria for adulthood based on gender, revealing that women have greater interdependency and family capacities than do men. This result is in tandem with the works of Cheah et al. (2010), Gilligan (1982), and Nelson et al. (2007), who all showed that women are traditionally more "otheroriented"- -thinking from perspectives other than their own and about the needs of others - and the main caregivers for children. Likewise, Ariffin (1999) noted that women have experienced tough times since they have to manage work and family, requiring them to be loving mothers at home and hardworking staff members in the workplace simultaneously. Additionally, these researchers affirmed that women possess stronger qualities in allocating more time and effort to family capacities than do men.

Accordingly, Koshal et al. (1998) stated that women have their own careers and can financially support themselves without having to rely on men. Past research has shown that there is significant improvement in a country's economic sector when women participate in the labor force (Ahmad 1998). Furthermore, women in Malaysia have achieved tertiary education level and are among the top scorers (Ismail et al. 2005).

Interdependency for women has also been seen in the division of household labor in traditional Malay communities. In his ethnographic studies, Firth (1966a) observed that Malay women often take control of family finances and act as bankers for their husbands. In another study, Firth (1966b) asserted that the role of women in the household economy was associated with the desire to be independent from action or income. In other words, married women were motivated to be independent from their husbands and not rely completely on their husbands' income.

There are also differences in the criteria for adulthood based on student status. Students placed greater emphasis on the role of transitions and biology in determining their adulthood than did nonstudents. Students have a close relationship with and are financially dependent on their parents since they have yet to complete their education and find employment to support themselves. These results are consistent with Arnett (2015)'s findings that emerging adulthood is seen as the process of reaching physical maturity and having the capacity for sexual reproduction. In addition, with the collectivist cultural norms and filial piety values of Sabahans, emerging adults feel less like adults in the presence of parents and friends.

\section{Limitations and Future Research}

Although this study has several strengths, there are limitations which should be considered when interpreting results. Malaysia has multiethnic, multicultural, and multilingual characteristics with separate cultural identities and beliefs. Thus, it is not possible to generalize the present findings to every Malaysian subgroup. Further research is therefore recommended to examine the diverse features of emerging adulthood beyond the Sabahan and the East Malaysian perspective. The differences between rural and low socioeconomic status populations and indigenous and religious groups may reveal more nuanced findings. While these findings provide important insights into the criteria for adulthood of emerging adults in Sabah (East Malaysia), future studies are recommended to explore conceptions of transition to adulthood. They should focus on those who live in rural and urban areas, since research that explores the criteria for emerging adulthood is difficult to assess explicitly and precisely.

\section{Conclusion}

This research makes a vital contribution to theoretical and managerial perspectives, especially in the Southeast Asian context. In terms of its theoretical implications, the present study delivers significant contributions to the emerging adulthood literature based on the criteria for adulthood as put forth. The findings are deemed vital since they echo those discoveries obtained in other collectivist cultures studies, such as those in China and India, in the sense that culture shapes and reinforces certain adulthood criteria. This addition enriches the application of the theory of emerging 
adulthood conceptualized by Arnett (2000). As a practical contribution, the study findings enable policymakers to obtain current views of emerging adults regarding the differences in criteria for adulthood based on gender. This view permits a better understanding of the value of emerging adults' mental health by exploring emerging adulthood roles and relationships. In this transitional stage of development from emerging adulthood to adulthood, young people encounter social, emotional, psychological, and physical challenges. This awareness facilitates the provision of appropriate developmental programs for emerging adults to assist young people in achieving adulthood.

\section{Compliance with Ethical Standards}

Conflict of interest The authors declare that they have no conflict of interest.

Ethical Approval All procedures performed in studies involving human participants were in accordance with the ethical standards of the institutional and/or national research committee and with the 1964 Helsinki declaration and its later amendments or comparable ethical standards.

Informed Consent Informed consent was obtained from all individual participants included in the study.

\section{References}

Ahmad, A. (1998). Country briefing paper: Women in Malaysia. Asian Development Bank Report.

Alavi, K. (2012). Dilema penjagaan ibu bapa tua. Bangi: Penerbit Universiti Kebangsaan Malaysia.

Ariffin, R. (1999). Feminism in Malaysia: A historical and present perspective of women's struggles in Malaysia. Women's Studies International Forum, 22(4), 417-423.

Arnett, J. J. (1997). Young people's conceptions of the transition to adulthood. Youth \& Society, 29(1), 3-23. https://doi. org/10.1177/0044118X97029001001.

Arnett, J. J. (1998). Learning to stand alone: The contemporary American transition to adulthood in cultural and historical context. Human Development, 41(5-6), 295-315. https://doi. org/10.1159/000022591.

Arnett, J. J. (2000). Emerging adulthood: A theory of development from the late teens through the twenties. American Psychologist, 55(5), 469-480. https://doi.org/10.1037/0003-066X.55.5.469.

Arnett, J. J. (2001). Conceptions of the transition to adulthood: Perspectives from adolescence through midlife. Journal of Adult Development, 8(2), 133-143.

Arnett, J. J. (2003). Conceptions of the transition to adulthood among emerging adults in American ethnic groups. New Directions for Child and Adolescent Development, 2003(100), 63-76.

Arnett, J. J. (2014). Emerging adulthood: The winding road from the late teens through the twenties. New York: Oxford University Press.

Arnett, J. J. (2015). The cultural psychology of emerging adulthood. In L. A. Jensen (Ed.), Oxford library of psychology. The Oxford handbook of human development and culture: An interdisciplinary perspective (pp. 487-501). Oxford: Oxford University Press.
Arnett, J. J. (2016). Does emerging adulthood theory apply across social classes? National data on a persistent question. Emerging Adulthood, 4(4), 227-235.

Barlocco, F. (2008). Between the local and the state: Practices and discourses of identity among the Kadazan of Sabah (East Malaysia) [Doctoral dissertation, Loughborough University, Leicestershire, UK].

Bernama (2019, July 24). Dewan Negara passes Amendment Bill to reduce youth age cap to 30 . Malay Mail. https://www.malay mail.com/news/malaysia/2019/07/24/dewan-negara-passe s-amendment-bill-to-reduce-youth-age-cap-to-30/1774495.

Brannen, J., \& Nilsen, A. (2002). Young people's time perspectives: From youth to adulthood. Sociology, 36(3), 513-537.

Browne, M. W., \& Cudeck, R. (1993). Alternative ways of assessing model fit. In K. Bollen \& J. Long (Eds.), Testing structural equation models (pp. 136-162). London: SAGE.

Chan, J. (2015, February 13). Sabah lists 42 ethnic groups to replace 'lain-lain' race column. Malay Mail. https://www.malaymail. $\mathrm{com} / \mathrm{s} / 840691 / \mathrm{sabah}$-lists-42-ethnic-groups-to-replace-lainlain-race-column.

Cheah, C. L., \& Nelson, L. J. (2004). The role of acculturation in the emerging adulthood of aboriginal college students. International Journal of Behavioral Development, 28(6), 495-507. https://doi.org/10.1080/01650250444000135.

Cheah, C. L., Trinder, K. M., \& Gokavi, T. N. (2010). Urban/rural and gender differences among Canadian emerging adults. International Journal of Behavioral Development, 34(4), 339-344. https://doi.org/10.1177/0165025409339152.

Deng, X., Sang, B., \& Chen, X. (2017). Implicit beliefs about emotion regulation and their relations with emotional experiences among Chinese adolescents. International Journal of Behavioral Development, 41(2), 220-227.

Department of Statistics Malaysia. (2019). Marriage and divorce statistics, Malaysia, 2019. https://www.dosm.gov.my/v1/index .php? $\mathrm{r}=$ column/cthemeByCat \&cat $=453 \&$ bul_id $=\mathrm{d} 1 \mathrm{BZV}$ zBZYXVwOTBPdXhGVEJTQW14dz09\&menu_id=L0phe U43NWJwRWVSZk1WdzQ4TlhUUT09.

Dogan, A., Yüzbası, D. V., \& Demir, M. (2015). The transition to adulthood in Turkey: Views from university students and workers. In R. Zukauskiene (Ed.), Emerging adulthood in a European context (pp. 94-114). Milton Park: Taylor \& Francis.

Eriksen, S., \& Gerstel, N. (2002). A labor of love or labor itself: Care work among adult brothers and sisters. Journal of Family Issues, 23(7), 836-856. https://doi.org/10.1177/019251302236597.

Facio, A., \& Micocci, F. (2003). Emerging adulthood in Argentina. New directions for child and adolescent development, 2003(100), 21-32.

Falk, R. F., \& Miller, N. B. (1992). A primer for soft modeling. Akron: University of Akron Press.

Firth, R. (1966a). Housekeeping among Malay peasants. London: The Athlone Press.

Firth, R. (1966b). Malay fisherman: Their peasant economy. London: Routledge and Kegan Paul.

Fornell, C., \& Larcker, D. F. (1981). Structural equation models with unobservable variables and measurement error: Algebra and statistics. Journal of Marketing Research, 18(3), 382-288.

Fung, H. H., \& You, J. (2011). Age differences in the likelihood of destructive anger responses under different relationship contexts: A comparison of mainland and Hong Kong Chinese. Psychology and Aging, 26(3), 605-611.

Galambos, N. L., \& Martínez, M. L. (2007). Poised for emerging adulthood in Latin America: A pleasure for the privileged. Child Development Perspectives, 1, 109-114.

Gilligan, C. (1982). In a different voice. Cambridge: Harvard University Press. 
Golingai, P. (2015, May 10). Sabahan first, then a Malaysian. The Star Online. https://www.thestar.com.my/news/nation/2015/05/10/ sabahan-first-then-a-malaysian-you-can-take-me-out-of-sabah -but-you-cant-take-sabah-out-of-me/.

Gom, D., Jiony, M. M., Tanakinjal, G. H., \& Siganul, R. S. (2015). Understanding cultural differences in ethnic employees' work values: A literature review. American Journal of Economics, 5(2), 112-118.

Hair, J. F., Black, W. C., Babin, B. J., \& Anderson, R. E. (2010). Multivariate data: A global perspective (7th ed.). London: Pearson Education Inc.

Hair, J. F., Sarstedt, M., Ringle, C. M., \& Gudergan, S. P. (2018). Advanced issues in partial least squares structural equation modeling. London: SAGE.

Hamzah, S. R. A., Suandi, T., Krauss, S. E., Hamzah, A., \& Tamam, E. (2014). Youth hedonistic behaviour: Moderating role of peer attachment on the effect of religiosity and worldview. International Journal of Adolescence and Youth, 19(4), 419-433.

Harris, L. C., \& Goode, M. M. H. (2004). The four levels of loyalty and the pivotal role of trust: A study of online service dynamics. Journal of Retailing, 80, 139-158.

Henig, R. M. (2010). What is it about 20-somethings? The New York Times Magazine. http://www.nytimes.com/2010/08/22/magaz ine/22Adulthood-t.html?pagewanted=all\&_r $=0$.

Hossain, Z., Roopnarine, J. L., Ismail, R., Hashmi, S. I., \& Sombuling, A. (2007). Fathers' and mothers' reports of involvement in caring for infants in Kadazan families in Sabah Malaysia. Fathering, 5(1), 58-72.

Hu, L. T., \& Bentler, P. M. (1999). Cutoff criteria for fit indexes in covariance structure analysis: Conventional criteria versus new alternatives. Structural Equation Modeling: A Multidisciplinary Journal, 6(1), 1-55.

Ishida, H. (2013). The transition to adulthood among Japanese youths: Understanding courtship in Japan. The ANNALS of the American Academy of Political and Social Science, 646(1), 86-106.

Ismail, M., Rasdi, R. M., \& Wahat, N. W. A. (2005). High-flyer women academicians: Factors contributing to success. Women in Management Review, 20(2), 117-132.

Jayson, S. (2012). Many "emerging adults" 18-29 are not there yet. USA Today. http://usatoday30.usatoday.com/news/health/welln ess/story/2012-07-30/Emerging-adults-18-29-still-attached-toparents/56575404/1

Jeffery, G. H., Lehr, R., Hache, G., \& Campbell, M. (1992). Empowering rural parents to support career development: An interior report. Canadian Journal of Counselling, 26(4), 240-255.

Katsiaficas, D., Suárez-Orozco, C., \& Dias, S. I. (2015). 'When do I feel like an adult?': Latino and Afro-Caribbean immigrant-origin community college students' conceptualizations and experiences of (emerging) adulthood. Emerging Adulthood, 3(2), 98-112.

Koshal, M., Gupta, A. K., \& Koshal, R. (1998). Women in management: A Malaysian perspective. Women in Management Review, 13(1), 11-18.

Liberska, H., Deja, M., Starostecka, J., Janicka, M., Grudzińska, A., Wolska, A., \& Dąbek, K. (2018). Identity and crisis in evaluation in young fathers in relation to age of the child. Health Psychology Report, 6(2), 126-135.

Lowe, S. R., Dillon, C. O., Rhodes, J. E., \& Zwiebach, L. (2013). Defining adult experiences: Perspectives of a diverse sample of young adults. Journal of Adolescent Research, 28(1), 31-68. https ://doi.org/10.1177/0743558411435854.

Luyckx, K., Schwartz, S. J., Goossens, L., \& Pollock, S. (2008). Employment, sense of coherence, and identity formation: Contextual and psychological processes on the pathway to sense of adulthood. Journal of Adolescent Research, 23(5), 566-591.
UNICEF Malaysia. (2019). Children out of school. https://www.unice f.org/malaysia/media/921/file/Out\%20of\%20School\%20children $\% 20 \% 20(\mathrm{OOSCI}) \% 20$ Accessible\%20version.pdf.

Minority Rights Group International. (2016). Malaysia - Indigenous peoples and ethnic minorities in Sabah. http://minorityrights.org/ minorities/indigenous-peoples-andethnic-minorities-in-sabah/.

Nelson, L. J. (2009). An examination of emerging adulthood in Romanian college students. International Journal of Behavioral Development, 33(5), 402-411. https://doi.org/10.1177/0165025409 340093.

Nelson, L. J., Badger, S., \& Wu, B. (2004). The influence of culture in emerging adulthood: Perspectives of Chinese college students. International Journal of Behavioral Development, 28(1), 26-36. https://doi.org/10.1080/01650250344000244.

Nelson, L. J., \& Luster, S. S. (2015). "Adulthood" by whose definition? The complexity of emerging adults' conceptions of adulthood. In J. J. Arnett (Ed.), Oxford handbook of emerging adulthood (pp. 421-437). Oxford: Oxford University Press.

Nelson, L. J., Padilla-Walker, L. M., Carroll, J. S., Madsen, S. D., Barry, C. M., \& Badger, S. (2007). "If you want me to treat you like an adult, start acting like one!" Comparing the criteria that emerging adults and their parents have for adulthood. Journal of Family Psychology, 21(4), 665-674. https://doi. org/10.1037/0893-3200.21.4.665.

Nelson, L. J., Xing Duan, X., Padilla-Walker, L. M., \& Luster, S. S. (2012). Facing adulthood: Comparing the criteria that Chinese emerging adults and their parents have for adulthood. Journal of Adolescent Research, 28(2), 189-208. https://doi. org/10.1177/0743558412467685.

Norona, J. C., Preddy, T. M., \& Welsh, D. P. (2016). How gender shapes emerging adulthood. In J. J. Arnett (Ed.), Oxford library of psychology. The Oxford handbook of emerging adulthood (pp. 62-86). Oxford: Oxford University Press.

O'Rourke, N., \& Hatcher, L. (2013). A step-by-step approach to using SAS for factor analysis and structural equation modeling. Cary: SAS Institute.

Pearson, E., \& Rao, N. (2003). Socialization goals, parenting practices, and peer competence in Chinese and English preschoolers. Early Child Development and Care, 173(1), 131-146.

Petrogiannis, K. (2011). Conceptions of the transition to adulthood in a sample of Greek higher education students. International Journal of Psychology \& Psychological Therapy, 11(1), 121-137. https:// doi.org/10.5964/ejop.v13i3.1327.

Pue, G. H., \& Sulaiman, N. (2013). "Choose one!": Challenges of inter-ethnic marriages in Malaysia. Asian Social Science, 9(17), 269-278.

Regis, P., Lasimbang, A., \& King, J. W. (1997, November 20-29). Introduction to integration of indigenous culture into non-formal education programmes in Sabah. Paper presented in the 15th Regional Workshop, Preparation of Literacy Follow-up Materials for Adults in Rural Areas in Asia and the Pacific, Kota Kinabalu, Sabah, Malaysia. http://www.accu.or.jp/litdbase/pub/dlper son/97rw/97RW_04.pdf.

Schlegel, A., \& BarryIii, H. (1991). Adolescence: An anthropological inquiry. New York: Free Press.

Seiter, L. N., \& Nelson, L. J. (2011). An examination of emerging adulthood in college students and nonstudents in India. Journal of Adolescent Research, 26(4), 506-536. https://doi. org/10.1177/0743558410391262.

Sokial, R. N. (2006). The Tambunan bamboo house: Its architecture, construction and taboos. Sabah Society Journal, 23, 7-18.

Statistics Austria. (2016). Births and marriages reflecting changes in Austrian society. http://ec.europa.eu/eurostat/statistics-explained/ index.php/Marriages_and_births_in_Austria. 
Syed, M., \& Mitchell, L. L. (2013). Race, ethnicity, and emerging adulthood: Retrospect and prospects. Emerging Adulthood, 1(2), 83-95.

Wallace, C., \& Kovatcheva, S. (1998). Youth in society. New York: Macmillan Press.

Weier, M., \& Lee, C. (2015). How do Australian university students understand adulthood? Australian Psychologist, 50(2), 157-167.

Westberg, A. (2004). Forever young? Young people's conception of adulthood: The Swedish case. Journal of Youth Studies, 7(1), $35-53$.

Wider, W., Bahari, F., Mustapha, M., \& Halik, M. (2016). Investigating the measurement of Malay version of Inventory of Dimensions of Emerging Adulthood (M-IDEA) among first year university students in Malaysia. International Journal of Current Research, 8(4), 29878-29884.

Wider, W., Halik, M. H., Mustapha, M., \& Bahari, F. (2015). A preliminary analysis of the perceptions of the five features of emerging adulthood: A comparison of perceived adult status among emerging adults in Malaysia. Projournal of Humanities and Social Science, 3(1), 12-24.

Wray-Lake, L., \& Syvertsen, A. K. (2011). The developmental roots of social responsibility in childhood and adolescence. New
Directions for Child and Adolescent Development, 2011(134), $11-25$.

Wyn, J., \& White, R. (1997). Rethinking youth. London: SAGE.

Xinhua. (2018). Across China: Chinese cities see rising marriage age. http://www.xinhuanet.com/english/2018-03/13/c_137036066.htm.

Yau, J., Smetana, J. G., \& Metzger, A. (2009). Young Chinese children's authority concepts. Social Development, 18(1), 210-229.

Yunus, A., \& Landau, E. (2019, July 3). 'Youth' now defined as those between 15 and 30. NewStraitsTime. https://www.nst.com.my/ news/nation/2019/07/501288/youth-now-defined-those-betwe en-15-and-30.

Zhong, J., \& Arnett, J. J. (2014). Conceptions of adulthood among migrant women workers in China. International Journal of Behavioral Development, 38(3), 255-265. https://doi.org/10.1177/01650 25413515133.

Publisher's Note Springer Nature remains neutral with regard to jurisdictional claims in published maps and institutional affiliations. 